\title{
Catalytic Oxidation of Cyclopentanol with
}

\section{N-Bromophthalimide}

\author{
Ankita Saraf ${ }^{1 *}$, S.P. Singh ${ }^{2}$, Arvind Prasad Dwivedi ${ }^{3}$ \\ ${ }^{I}$ Department of Chemistry, Pt. S.N.S. Govt. P.G. College (NAAC) Shahdol (M.P.) India \\ ${ }^{2}$ Department of Chemistry, Govt. I.G. H. Sc. P.G. College Shahdol (M.P.) India \\ ${ }^{3}$ Department of Chemistry, Govt. Sanjay Gandhi Smrati Auto., P.G., College Sidhi M.P
}

*Corresponding Author: Ankita Saraf, Department of Chemistry, Pt. S.N.S. Govt. P.G. College (NAAC)

Shahdol (M.P.) India

\begin{abstract}
The tungustophosphoric acid catalysed oxidation of cyclic alcohol (Cyclopentanol) by $N$ bromophthalimide (NBP) in 50\% aqueous acetic acid medium in absence of mercuric (II) acetate and in presence of mineral acid was reported spectrophotometrically. The available spectral data was used for the verification of Beer-Lambert Law. The study reveals first-order kinetics for oxidant whereas fractional-order for substrate and catalyst PTA. The presence of mineral acid had insignificant effect whereas phthalimide shows retarding trends while increase in solvent polarity shows increase in rate of oxidation. A reasonable complex mechanism with mole ratio 1:1 was proposed consistent with the kinetic findings supported by thermodynamic parameters.
\end{abstract}

Key words: Consistent, versatile, investigation, suppression, retardation.

\section{INTRODUCTION}

NBP is a potential oxidizing agent, versatile in nature on hydrolysis produces $\mathrm{HOBr}$ reacting species extensively used in the oxidation of alcohols, 1 benzhydrols, 2 amino acids, 3 hydroxy acids 4 etc., whereas PTA a Keggin type anionic catalyst due to its thermal stability and acidity finds commendable position in Inorganic chemistry and is of academic importance in national and international laboratories. The kinetic oxidative studies of several organic compounds viz. aromatic alcohols, 5 benzyl alcohols, 6 involving PTA have been investigated. Cyclopentanol is a monohydric cyclic alcohol, shows a variety of reactions with different number of oxidants $\mathrm{KBrO} 3,7 \mathrm{NCP}, 8 \mathrm{QDC}, 9$ NBA,10 CAT11, Ce(IV)12, Ru(III)13. However, there is no report available on the possible reaction mechanism or its selectivity under special condition with NBP spectrophotometrically. Hence this has prompted authors to undertake the task of kinetic investigation.

\section{Materials And Methods}

All chemicals were reagent grade (B.D.H., C.D.H., Analar LOBA) and were used without further purification. All the required solutions used in this investigation, are freshly prepared and after kept in dry \& cool places. The stability of the solution was tested under same operating conditions. A UVvisible double beam spectrophotometer of standard model fitted with cells was used in the experiments. The catalytic oxidation reactions were carried out in a $500 \mathrm{ml}$ glass reaction vessel with variable speed stirrer, a condenser and a jacket for the circulation of the thermo regulating fluid. The temperature of the water or solution was regulated with a precision of $\pm 0.1^{\circ} \mathrm{C}$ by an external thermostat. The concentration of the NBP species was determined spectrophotometrically at their respective absorption maxima.

\subsection{Kinetic Measurement}

The kinetic study of the PTA catalysed reaction was approached by the method of initial velocities, carrying the concentration of one reagent at a time. The calculated amount of NBP solution was added 
to the cyclopentanol with different reagents in appropriate concentrations.

The progress of reaction kinetics was monitored spectrophotometrically followed by the reduction reaction and measuring its decrease in absorption/optical activity for unreacted NBP at wave length $=$ $238.6 \mathrm{~nm}$. The observed data was fed in equation $\mathrm{k}=1 / \mathrm{t} \mathrm{In}_{\mathrm{D}_{\mathrm{o}}}-\mathrm{D}_{\mathrm{e}} / \mathrm{D}_{\mathrm{t}}-\mathrm{D}_{\mathrm{e}}$ to calculate rate constants.

\section{RESULTS AND DISCUSSION}

The PTA catalytic reaction was studied under [Cyclopentanol] $>[\mathrm{NBP}]$ at experimental temperature in aqueous acetic acid medium in presence of mineral acid $\mathrm{H} 2 \mathrm{SO} 4$ at temperature $308 \mathrm{~K}$ using UVvis. Spectrometer at peak $\lambda_{\max }=238.6 \mathrm{~nm}$. The spectral data follow the Beer-Lambert law from the veracity of the plot drawn between optical density/ absorbance and [NBP] (Table 1, Fig.1). The unit slope of linear plot suggested that the order with respect to halooxidant [NBP] is one. The spectral data of kinetics for cyclopentanol within concentration range $1.50 \times 10-2$ to $5.0 \times 10-2(\mathrm{~mol} \mathrm{dm}-3)$ have been collected. The spectrophotometric study shows fractional-order with respect to substrate. The study provides an evidence for complex kinetics between reacting species $\mathrm{HOBr}$ of oxidant (NBP) and substrate which is supported by double reciprocal linear plot of k-1 vs. 1/[S] with yielding positive intercept on Y-axis.

Table1. Effect of concentration of oxidant $(N B P)$ on rate of oxidation

$[$ Cyclopentanol $]=2.50 \times 10-2(\mathrm{~mol} \mathrm{dm}-3) ; \quad[\mathrm{PTA}]=2.50 \times 10-4(\mathrm{~mol} \mathrm{dm}-3) ;$

$[\mathrm{H}+]=0.80 \times 10-3(\mathrm{~mol} \mathrm{dm}-3) ; \quad \mathrm{HOAc}-\mathrm{H} 2 \mathrm{O}=30 \%(\mathrm{v} / \mathrm{v}) ;$

Temperature $=308 \mathrm{~K} ; \lambda \max =238.6 \mathrm{~nm}$

\begin{tabular}{|c|c|c|c|}
\hline S. No. & Time(min.) & Optical Density & {$[\mathbf{N B P}] \times \mathbf{1 0}{\left.\mathbf{~} \mathbf{~ m o l ~} \mathbf{~ d m}^{-3}\right)}^{-3}$} \\
\hline 1. & 0.00 & 0.650 & 6.00 \\
\hline 2. & 0.60 & 0.551 & 5.00 \\
\hline 3. & 1.20 & 0.436 & 4.50 \\
\hline 4. & 1.50 & 0.414 & 4.00 \\
\hline 5. & 2.00 & 0.380 & 3.00 \\
\hline 6. & 3.00 & 0.270 & 2.50 \\
\hline 7. & 4.00 & 0.251 & 2.00 \\
\hline 8. & 5.00 & 0.173 & 1.25 \\
\hline 9. & 5.50 & 0.123 & 1.00 \\
\hline 10. & 6.00 & 0.101 & \\
\hline
\end{tabular}

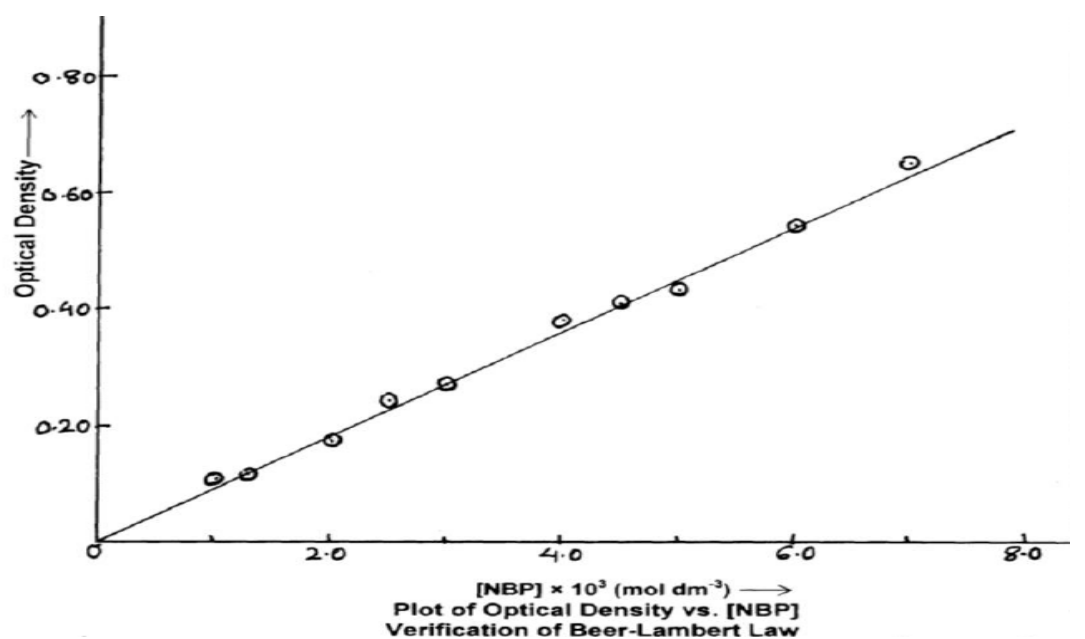

Figure1. $\left[\right.$ Cyclopentanol] $=2.50 \times 10^{-2}\left(\mathrm{Mol} \mathrm{Dm}^{-3}\right) ;[\mathrm{PTA}]=2.5 \times 10^{-4}\left(\mathrm{Mol} \mathrm{Dm}^{-3}\right) ;\left[\mathrm{H}^{+}\right]=0.80 \times 10^{-3}(\mathrm{Mol}$ $\left.\mathrm{Dm}^{-3}\right) ; \mathrm{Hoac}-\mathrm{H}_{2} \mathrm{O}=30 \%(\mathrm{~V} / \mathrm{V}) ;$ Temperature $=308 \mathrm{~K} ; \lambda_{\operatorname{Max}}=238.6 \mathrm{Nm}$

In the next series of experiments, the spectral kinetic data have been obtained for almost five times variation of $\mathrm{H}_{2} \mathrm{SO}_{4}$ at fixed concentration of other reagents, temperature and wavelengths. The study shows that $\mathrm{H}_{2} \mathrm{SO}_{4}$ had no appreciable effect on spectral absorption or rate of oxidation.

Though phosphotungustic acid (PTA) is anion of Keggin type $\left[\mathrm{PW}_{12} \mathrm{O}_{40}\right]^{3-}$ catalyst, employed in the investigation exhibits fractional-order kinetics at its higher concentration and forms complex with 
substrate by loosing one molecule of water and release protons during the course of study. In presence of mineral acid it causes suppression and forms the complex. The wavelength of PTA has been found, to reduce during study of the substrate. It is possible to show that variation in the binary composition of solvent polarity, acetic acid and water (20 to 50\%) increases the rate of oxidation with increasing percentage composition of acetic acid (Table 2). The Amis ${ }^{14}$ plot of log k vs. 1/D gives positive slope (Fig.2).

The addition of varying concentration of $\mathrm{NaCl}$ neutral salt had a nominal effect on the rate of oxidation indicating that one of the neutral species of the reagent is involved in the reaction kinetics. The added reaction product phthalimide indicates slightly retardation trends in the rate of oxidation. Activation parameter for the reactions have been determined for the catalytic reactions at four different temperatures $\left(30^{\circ}, 35^{\circ}, 40^{\circ}\right.$ and $\left.45^{\circ} \mathrm{C}\right)$ and two concentrations $\left[2.0 \times 10^{-2}\right.$ and $2.50 \times 10^{-2}$ (mol $\left.\mathrm{dm}^{-3}\right)$ ]. The values have been demonstrated in (Table 3). The study rules out the presence of free radicals when tested with polyacrylonitrile. The stoichiometry of the reaction was ascertained which revealed 1:1 mole ratio of cyclopentanol and oxidant NBP. The cyclopentanone was obtained as a reaction product which was identified by determining its melting point, and also forming its 2,4-DNP derivatives. ${ }^{15}$ The cyclopentanone was also confirmed by chromatographic and IR methods.

Table2. Effect of Dielectric Constant of the Medium on Rate of Oxidation

$[$ Cyclopentanol $]=2.50 \times 10^{-2}\left(\mathrm{~mol} \mathrm{dm}{ }^{-3}\right) ; \quad[N B P]=5.0 \times 10^{-3}\left(\mathrm{~mol} \mathrm{dm}^{-3}\right)$;

$[\mathrm{PTA}]=2.50 \times 10^{-4}\left(\mathrm{~mol} \mathrm{dm}^{-3}\right) ; \quad\left[\mathrm{H}^{+}\right]=0.80 \times 10^{-3}\left(\mathrm{~mol} \mathrm{dm}^{-3}\right)$;

Temperature $=308 \mathrm{~K} ; \lambda_{\max }=238.6 \mathrm{~nm}$

\begin{tabular}{|c|c|c|c|}
\hline $\begin{array}{c}\text { S. } \\
\text { No. }\end{array}$ & $\mathbf{C H}_{\mathbf{3}} \mathbf{C O O H}-\mathbf{H}_{\mathbf{2}} \mathbf{O} \%(\mathbf{v} / \mathbf{v})$ & $\mathbf{1 0}^{3} / \mathbf{D}$ & $\mathbf{1 0}^{\mathbf{4}} \mathbf{k}\left(\mathbf{s}^{-\mathbf{1}}\right)$ \\
\hline 1. & 20 & 17.17 & 35.65 \\
\hline 2. & 30 & 19.15 & 38.17 \\
\hline 3. & 40 & 21.98 & 42.28 \\
\hline 4. & 50 & 25.64 & 46.90 \\
\hline
\end{tabular}

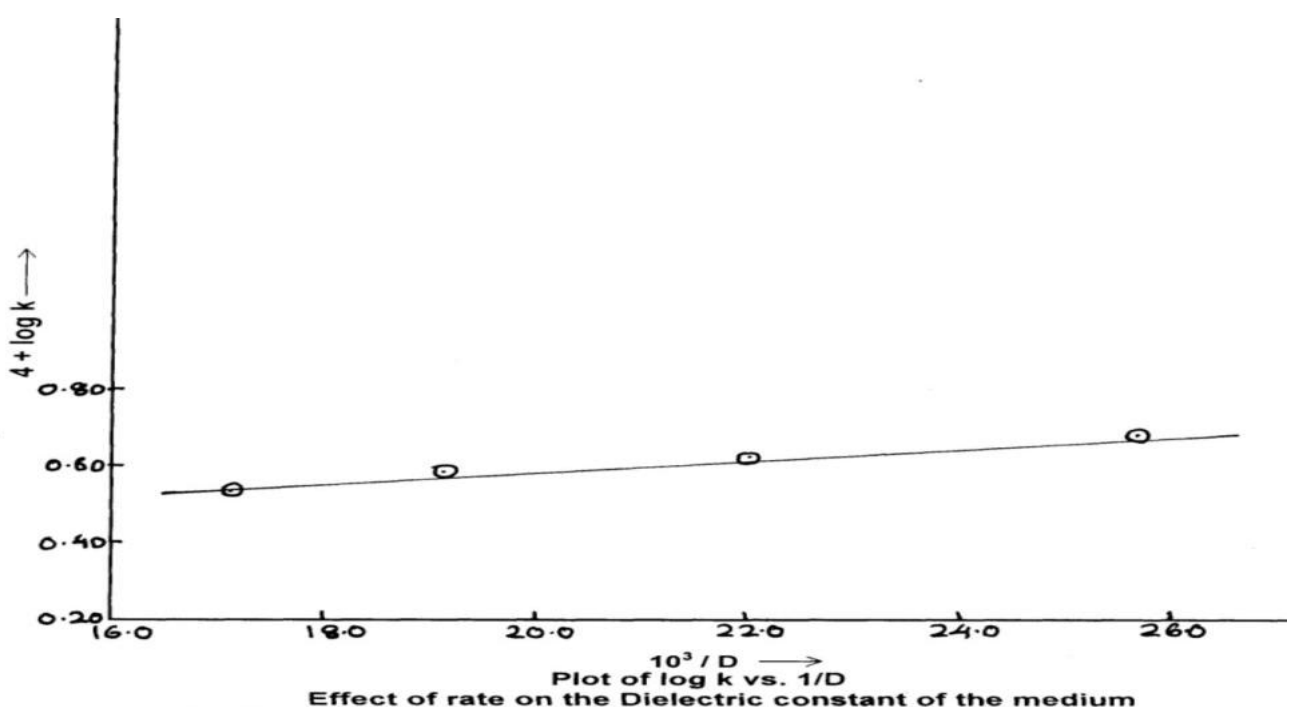

Figure2. [Cyclopentanol] $=2.50 \times 10-2(\mathrm{~mol} \mathrm{dm}-3) ;[\mathrm{NBP}]=5.0 \times 10-3(\mathrm{~mol} \mathrm{dm}-3) ;[P T A]=2.50 \times 10-4(\mathrm{~mol}$ dm-3); $[\mathrm{H}+]=0.80 \times 10-3(\mathrm{Mol} \mathrm{Dm}-3) ;$

Temperature $=308 \mathrm{~K} ; \lambda$ Max $=238.6 \mathrm{~nm}$

Table3. Activation Parameters for Catalysed PTA Oxidation of Cyclopentanol- NBP System

\begin{tabular}{|c|c|c|c|c|c|c|}
\hline S.No. & Substrate & ${\mathrm{Ea} \mathrm{kJ}\left(\mathrm{mol}^{-1}\right)}^{\mathrm{A}\left(\mathrm{s}^{-1}\right)}$ & $\Delta \mathrm{H}^{\#} \mathrm{~kJ}\left(\mathrm{~mol}^{-1}\right)$ & $\Delta \mathrm{G}^{\#} \mathrm{~kJ}\left(\mathrm{~mol}^{-1}\right)$ & $\Delta \mathrm{S}^{\#} \mathrm{JK}^{-1}\left(\mathrm{~mol}^{-1}\right)$ \\
\hline 1. & Cyclopentanol & 38.09 & $9.62 \times 10^{2}$ & 35.53 & 86.46 & -163.99 \\
\hline
\end{tabular}

\subsection{Reaction Mechanism and Rate Law}

On the basis of kinetic results and considering $\mathrm{HOBr}$ a prime oxidizing species, the probable mechanism is proposed: 


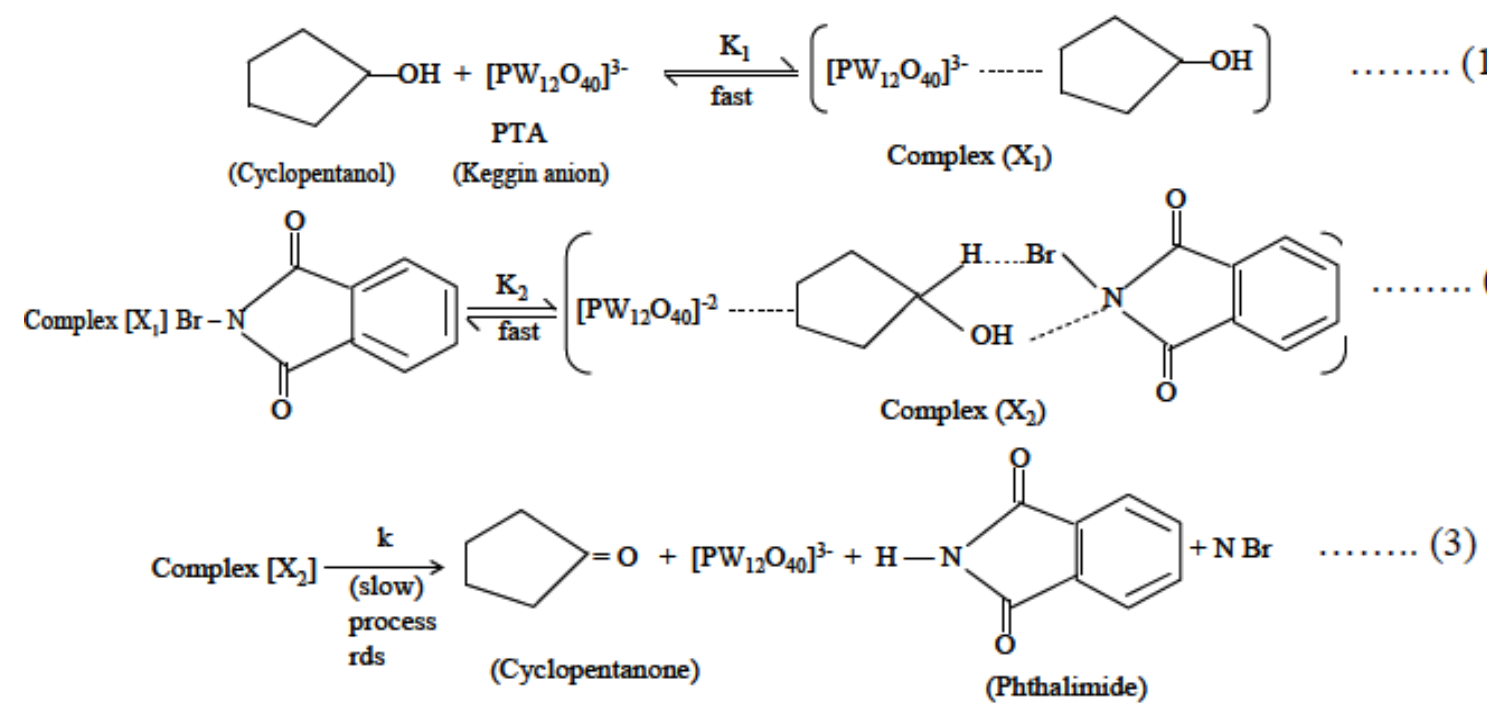

\section{Rate Law}

$$
\begin{aligned}
& \mathrm{X}_{1}+[\mathrm{NBP}] \underset{\text { fast }}{\rightleftharpoons} \text { Complex } \mathrm{X}_{2}
\end{aligned}
$$

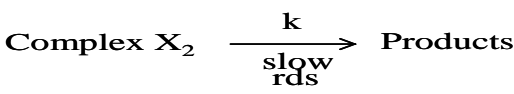

The rate of reaction may be obtained in terms of consumed [NBP] as given below:

$$
\frac{-\mathrm{d}[\mathrm{NBP}]}{\mathbf{d t}}=\mathbf{k}\left[\mathrm{X}_{2}\right]
$$

In view of taking various steps involved in the formation of complex, the final rate law is obtained as

$$
\mathrm{k}_{\mathrm{obs}}=\frac{\mathrm{k} \mathrm{K}_{2} \mathrm{~K}_{1}[\mathrm{PTA}][\mathrm{S}]}{1+\mathrm{K}_{1}[\mathrm{~S}]+\mathrm{K}_{1} \mathrm{~K}_{2}[\mathrm{~S}]}
$$

The equation (5) can also be transformed as:

$$
\frac{[\mathrm{PTA}]}{\operatorname{rate}\left(\mathrm{k}^{\prime}\right)}=\frac{1}{\mathrm{k} \mathrm{K}_{1} \mathrm{~K}_{2}[\mathrm{~S}]}+\frac{1}{\mathrm{k} \mathrm{K}_{2}}
$$

The equations (5) and (6) of rate law explain all the kinetic results catalysed by PTA.

A couple of authors ${ }^{\mathbf{8}, 16}$ have also supported the similar type of mechanism operative in cyclic alcohols reactions studied by different oxidants NCP etc.

\section{CONCLUSION}

The formation of ternary complex between catalyst (PTA), $\mathrm{HOBr}$ and substrate have been discussed. The influence of PTA in suppression of $\left[\mathrm{H}^{+}\right]$, fractional-order kinetics with respect to cyclopentanol, and PTA was explained. The $\mathrm{HOBr}$ was postulated as prime reacting species of oxidant. The thermodynamic parameters were determined.

\section{REFERENCES}

[1] Nath, N. and Dubey, R.C., Indian J. Chem., 1982, 21, 244.

[2] Bharad Jagdish, V., Madje Balaji, R., and Libale Limind, B., Int. J. Chem. Tech. Res., 2010, Vol. 2, No.1, pp. 346-353.

[3] Singh, A.K., Jain, B., Negi, R., Katre, Y., and Singh, S.P., the Open Catalysis J., 2009, 2, 12-20.

[4] Patil, S., Katre, Y.R. and Singh, A.K.: J. Surfactants and Detergents, 2007, Vol. 10, No.3, 175-184.

[5] Bharad, J., Madje, B., Fulchand, C., Farooqui, M. and Ubale, M., Bull. Chem. Soc., India, 2008, 7, 168176.

[6] Gupta, H.D., Singh, S.K., and Singh, Santosh Kumar, J. Chem. Bio. And Phy. Sc., 2012, Vol.2, No.4. 
[7] Sewanee, J.P., Valechha, Anita, Singh, Alka, and Valechha, N.D., J. Indian Chem. Soc., 1980, 70-76.

[8] Bharad, Jagdish, Balaji Madje, Fulchand Charan, Mazahar, Farooqui and Milind Ubale, J. Phy. Chem., 2008, Vol.3, issue 2-3.

[9] Nongkynrih, I., and Mohanti, M.K., Bull. Chem. Soc., Japan, 1996, 69, 1403-1407.

[10] Shrivastava, A., Awasthi, and Singh, K., Int. J. Chem. Kinet., 2005, 37, 275.

[11] Prabhu, D.V., Oriented J. of Chem. 2008, Vol. 24(1), 163-166.

[12] Herold, L., Hintz, L. and Johnson, D.C., Am. Chem. Soc., Phoenix Art Jan. 1966.

[13] Shrivastava, S., Singh, K., Shukla, M. and Pandey, N., Oxid. Commun, 2001, 24, 558.

[14] Amis, E.S., Solvent Effect on Reaction Rates and Mechanism, Academic Press, Newyork, 1962, pp. 733.

[15] Vogel, I., Elementary Practical Organic Chemistry, Pearson, Education Publication, 2010.

[16] Tiwari, S.N., Dwivedi, H.P., Khan, Khushbo, Nusrat Babey and Chauhan, R.P.S., Intl. J. Creative Res. Thoughts, 2015, Vol. 3 (6) 1-4.

Citation: Saraf, A. et.al. (2019). "Catalytic Oxidation of Cyclopentanol with N-Bromophthalimide". International Journal of Advanced Research in Chemical Science (IJARCS), 6(2), pp.19-23. DOI: http://dx.doi.org/ 10.20431/2349-0403.0602001

Copyright: (c) 2019 Authors. This is an open-access article distributed under the terms of the Creative Commons Attribution License, which permits unrestricted use, distribution, and reproduction in any medium, provided the original author and source are credited. 